\title{
Strategies to Get Drugs across Bladder Penetrating Barriers for Improving Bladder Cancer Therapy
}

\author{
Shupeng Wang ${ }^{1}$, Shaohua Jin ${ }^{1}$, Qinghai Shu ${ }^{1, *(1)}$ and Song $\mathrm{Wu}^{2, *}$ \\ 1 School of Material Science and Engineering, Beijing Institute of Technology, Beijing 100081, China; \\ 3120170538@bit.edu.cn (S.W.); jinshaohua@bit.edu.cn (S.J.) \\ 2 School of Medicine, Shenzhen University, Shenzhen 518000, China \\ * Correspondence: qhshu121@bit.edu.cn (Q.S.); wusong@szu.edu.cn (S.W.)
}

\section{check for}

updates

Citation: Wang, S.; Jin, S.; Shu, Q.; $\mathrm{Wu}, \mathrm{S}$. Strategies to Get Drugs across Bladder Penetrating Barriers for Improving Bladder Cancer Therapy. Pharmaceutics 2021, 13, 166. https://doi.org/10.3390/ pharmaceutics13020166

Received: 13 January 2021

Accepted: 21 January 2021

Published: 27 January 2021

Publisher's Note: MDPI stays neutral with regard to jurisdictional claims in published maps and institutional affiliations.

Copyright: (c) 2021 by the authors. Licensee MDPI, Basel, Switzerland. This article is an open access article distributed under the terms and conditions of the Creative Commons Attribution (CC BY) license (https:// creativecommons.org/licenses/by/ $4.0 /)$.

\begin{abstract}
Bladder cancer is a significant public health concern and social burden due to its high recurrence risk. Intravesical drug instillation is the primary therapy for bladder cancer to prevent recurrence. However, the intravesical drug therapeutic effect is limited by bladder penetrating barriers. The inadequate intravesical treatment might cause the low drug concentration in lesions, resulting in a high recurrence/progression rate of bladder cancer. Many strategies to get drugs across bladder penetrating barriers have been developed to improve intravesical treatment, including physical and chemical methods. This review summarizes the classical and updated literature and presents insights into great therapeutic potential strategies to overcome bladder penetrating barriers for improving the intravesical treatment of bladder cancer.
\end{abstract}

Keywords: intravesical treatment; drug instillation; bladder cancer; bladder penetrating barriers; urothelium; bladder mucosa

\section{Introduction}

Bladder cancer is one of the most common urinary system tumors, ranking among the 10 most common malignancies worldwide [1]. Bladder cancer is classified into non-muscle invasive bladder cancer (NMIBC) and muscle invasive bladder cancer (MIBC), the proportions are approximately $70 \%$ and $30 \%$, respectively [2]. The occurrence and progression of bladder cancer are heterogeneous, resulting in various clinical outcomes, and nearly 170,000 cases died from this disease every year in the world [3-5]. Transurethral resection of bladder tumor (TURBT) is the first-line treatment for bladder cancer. The subsequent intravesical instillation of Bacillus Calmette-Guérin (BCG) and chemotherapeutic drugs are used to prevent cancer recurrence. However, up to $50 \%$ of patients still have tumor recurrence within 5 years [6,7]. The reason of bladder cancer recurrence is difficult to explain, which may be related to the existence of cancer stem cells, tumor dissemination, and sporadic tumor micro foci after TURBT [8,9]. On the condition that intravesical instillation cannot effectively kill the residual bladder cancer cells, recurrence may occur. Patients with a high risk of recurrence/progression do poorly on currently recommended therapeutic regimens, so alternative schedules are urgently required [6].

In the last 10 years, high-throughput genome sequencing has revealed genomic characterization of bladder cancer [10], and immune checkpoint inhibitors are applied to the treatment of advanced urothelial carcinoma [11,12]. However, bladder cancer is still a significant public health concern and social burden due to its high recurrence risk, associated with considerable treatment costs [13]. To reduce the potential risk of bladder tumor recurrence and treatment failures, effective therapy still needs enough attention, especially reliable intravesical drug instillation. 


\section{Drugs of Intravesical Treatment}

\subsection{Immunotherapy}

Bacillus Calmette-Guérin (BCG) is the live attenuated vaccine form of Mycobacterium bovis, which is primarily used against tuberculosis [14,15]. Intravesical BCG to treat bladder cancer is since 1976, BCG can induce immune responses in the bladder mucosa to treat residual tumors after TURBT and prevent the recurrence/progression of bladder cancer, which is the currently recommended therapy [16]. However, intravesical BCG is possible to induce severe stimulus response, even cause dysuria, hematuria, and cystitis [17]. To reduce adverse events of intravesical immunotherapy, the attenuated Salmonella Enterica Typhi Ty21a vaccine-strain (Ty21a) may take place of BCG. The pre-clinical data demonstrates that Ty21a has excellent efficacy and safety. Th1-type immune responses induced by Ty21a are similar to that of BCG, besides, Ty21a is more effective than BCG to anti-tumor capacity in the established bladder cancer model [18].

\subsection{Chemotherapy}

For intravesical chemotherapy, epirubicin, doxorubicin (DOX), mitomycin (MMC), and gemcitabine are the most common agents. In addition to drug species, the intravesical chemotherapeutic effect is also related to urine $\mathrm{pH}$, instillation time, and the concentration of chemotherapy drugs [19]. Multiagent combined intravesical chemotherapy has been proposed in recent years [20-22]. Such intravesical multiagent regimens have the potential to offer better efficacy than conventional intravesical chemotherapy, which may also be an alternative to patients who are unresponsive or tolerant to BCG [23-25].

\subsection{Photodynamic Therapy}

Intravesical photodynamic therapy is an alternative strategy for bladder cancer. When the photosensitizer is activated by laser light with a specific wavelength, the photosensitizer will react with oxygen to generate singlet oxygen to destroy bladder cancer cells [26-29]. Commonly used photosensitizers include hematoporphyrin and 5-aminolevulinate [30,31]. Photodynamic therapy has showed encouraging therapeutic effects, but it also leads to toxicity on normal cells. In the future, the antibody-conjugate photosensitizer will be a more target agent for intravesical photodynamic therapy [29].

\subsection{Gene Therapy}

Intravesical gene therapy has achieved satisfactory results for bladder cancer treatment in clinical trials, especially for high-risk BCG-unresponsive NMIBC [32-35]. CG0070 is a gene therapy based on the oncolytic adenovirus containing a cancer-target promoter and a granulocyte-macrophage colony-stimulating factor (GM-CSF) gene. CG0070 can kill bladder cancer cells through cell lysis based on oncolytic adenovirus and immunemediated cell killing induced by GM-CSF. The Phase II clinical trial have showed that in high-risk NMIBC patients who are refractory or have relapsed from BCG therapy, intravesical CG0070 results in overall 44\% and 30\% complete response rates at 6 and 12 months, respectively [33]. Different from CG0070, rAd-IFN/Syn3 gene therapy is based on the non-replicating recombinant adenovirus encoding the interferon alpha- $2 b$ (IFN- $\alpha 2 b)$ gene, and Syn 3 is a transfect enhancer [35]. In the Phase III Study of rAd-IFN/Syn3, more than half of the patients with high-grade NMIBC achieved a complete response at 3 months [36].

\section{Advantages and Challenges of Intravesical Instillation}

Due to the bladder's unique anatomical characteristics, intravesical therapy is preferred over the oral and intravenous routes for treating bladder cancer [37]. In most cases of oral and intravenous route, only a small fraction of drugs reach desired lesions, owing to loss from systemic metabolism or poor absorption. In contrast, intravesical treatment is a non-invasive drug administration route through a catheter, which is expected to maxi- 
mize lesions exposure to the therapeutic agent, minimizing or even eliminating systemic side effects.

The efficacy of intravesical instillation depends on effective drug penetration into bladder tumors. However, the low permeability of bladder penetrating barriers limits the drug concentration of bladder tissues. With the excretion of urine, the intravesical drug failed to penetrate the bladder will be diluted or washed out, reducing the effect of intravesical treatment.

\section{Bladder Penetrating Barriers}

The bladder is a spherical hollow organ to store urine and urinate. The bladder wall is composed of several layers, the serosa, muscularis propria, the submucosal layer, and the mucosa (urothelium) [38]. The urothelium is multilayered, consisting of a layer of superficial umbrella cells, several layers of intermediate cells, and a layer of basal cells, as shown in Figure 1. The umbrella cells are connected by tight junctions, which prevent the paracellular diffusion of substances $[39,40]$. The urothelium is considered impenetrable to the vast majority of all the urine substances present [40,41]. Glycosaminoglycan (GAG) is located at the urothelial luminal surface to form the negatively charged GAG layer, also contributing to urothelial barrier function [42-44].

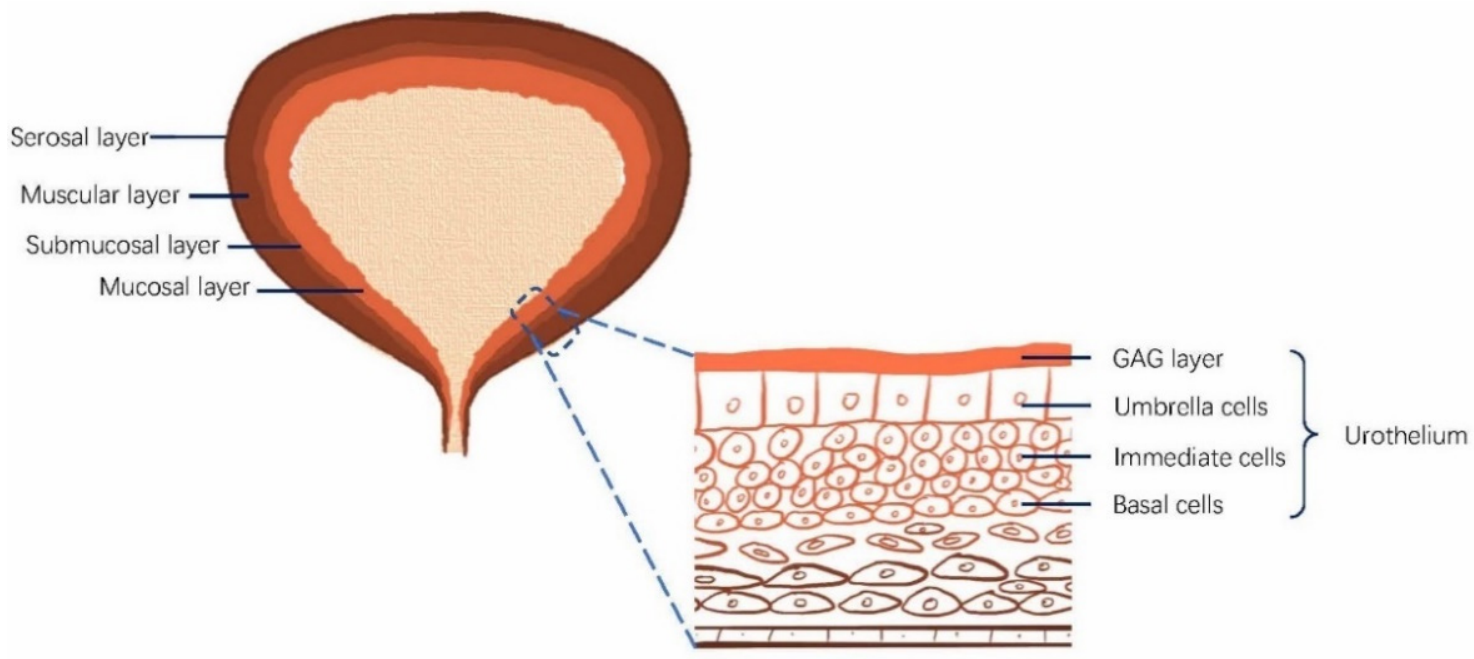

Figure 1. Bladder structure and the urothelium. The urinary bladder walls comprise four layers: the mucosa (urothelium), the submucosal layer, the muscular layer, and the serosal layer. The urothelium includes umbrella cells, intermediate cells, and basal cells. Glycosaminoglycan (GAG) is located at the urothelial luminal surface to form the negatively charged GAG layer, contributing to the bladder barrier function.

The distinctive structure of the urothelium with a high transepithelial electrical resistance provides a permeation barrier, also known as the bladder permeability barrier [45-47]. The bladder permeability barrier prevents the penetration of bacteria and harmful substances from urine into the blood. Meanwhile, the barrier imposes restrictions on passive diffusion of intravesical drugs. Therefore, opening the bladder permeability barrier is of great significance to effective intravesical instillation to treat bladder cancer. Herein, chemical and physical means to get drugs across bladder penetrating barriers are presented in Figure 2, and the development stage of each strategy has been detailed in Table 1. 


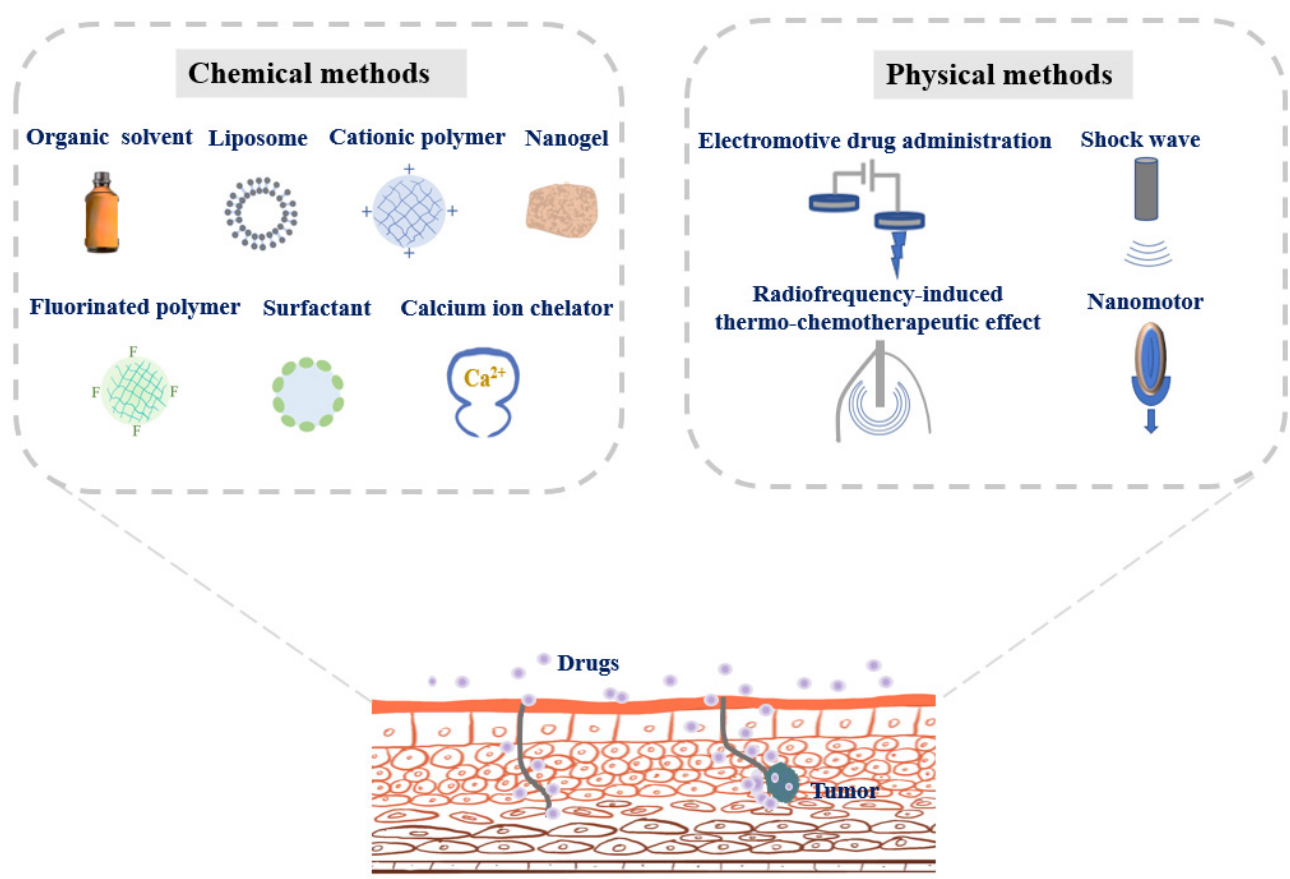

Figure 2. Chemical and physical strategies to get drugs across bladder penetrating barriers for improving bladder cancer therapy.

Table 1. The development stage of each strategy to get drugs across bladder penetrating barriers for improving bladder cancer therapy.

\begin{tabular}{|c|c|c|c|}
\hline & Strategy & Preclinical Development & Under Clinical Trials \\
\hline \multirow{18}{*}{ Chemical methods } & \multirow{3}{*}{ Organic solvents } & DMSO/epirubicin [48] & \\
\hline & & Acetone/BCG [49] & \\
\hline & & Ethanol/adenovirus [50] & \\
\hline & \multirow{4}{*}{ Cationic polymers } & PEG-PAMAM/DOX [51] & \\
\hline & & Chitosan-PLGA NPs [52] & \\
\hline & & Chitosan/IL-12 [53] & \\
\hline & & PGON-PLGA NPs [54] & \\
\hline & Fluorinated polymers & $\begin{array}{l}\text { Fluorinated polyethylenimine/peptide [55] } \\
\text { Fluorinated chitosan/sonosensitizer [56] }\end{array}$ & \\
\hline & \multirow{2}{*}{ Liposomes } & Maleimide-modified PEGylated liposomes [57] & \multirow{2}{*}{ Proliposomal paclitaxel [59] } \\
\hline & & In situ-gelling liposome-in-gel/paclitaxel [58] & \\
\hline & \multirow{4}{*}{ Surfactants } & Sodium dodecyl sulfate [50] & \multirow{4}{*}{$\begin{array}{c}\text { rAd-IFN/Syn3 [63] } \\
\text { CG0070/dodecyl-beta-D- } \\
\text { maltoside [32] }\end{array}$} \\
\hline & & Cetylpyridinium chloride [60] & \\
\hline & & Tween 80/doxorubicin [61] & \\
\hline & & Brij 98-containing nanoemulsions/cisplatin [62] & \\
\hline & \multirow{2}{*}{ Calcium ion chelators } & Polycarbophil [64] & \\
\hline & & EDTA-based nano-platform [65] & \\
\hline & \multirow{2}{*}{ Nanogels } & (PLL-P(LP-co-LC)) nanogel [66] & \\
\hline & & R9-PEG-P(LP-co-LC) nanogel [67] & \\
\hline \multirow{5}{*}{ Physical methods } & EMDA & & EMDA/MMC $[68,69]$ \\
\hline & RITE & & RITE/MMC $[70,71]$ \\
\hline & Shock wave & Low-energy shock wave therapy [72] & \\
\hline & \multirow{2}{*}{ Nanomotors } & Asymmetrically modified platelets [73] & \\
\hline & & Polydopamine-based nanomotors [74] & \\
\hline
\end{tabular}




\section{Chemical Methods to Get Drugs across Bladder Penetrating Barriers \\ 5.1. Organic Solvents}

Dimethylsulfoxide (DMSO) is a dipolar solvent, miscible with lipid and water. DMSO can affect the lipid bilayer, thereby increasing the drug penetration in cytomembrane and biological barriers. DMSO has also been approved by U.S. Food and Drug Administration (FDA) for interstitial cystitis/bladder pain syndrome, which proved DMSO is safe for intravesical instillation [75]. Co-administration of DMSO can promote small molecule drugs across the urothelium [76,77]. Yaman et. found intravesical instillation of epirubicin with DMSO enhanced the epirubicin absorption of the bladder wall, the fluorescence of epirubicin was observed throughout the bladder tumor and in the deeper muscle layers. In contrast, epirubicin's fluorescence was only seen in the bladder mucosa in the epirubicin without DMSO group [48]. Acetone has been shown to improve BCG attachment to the bladder wall by removing the bladder mucosa [49]. Ramesh et al. reported intravesical ethanol pretreatment enhanced adenovirus-mediated gene transfer in both normal and neoplastic urothelium, indicating ethanol also destroyed the bladder barriers [50].

\subsection{Cationic Polymers}

Polyamidoamine (PAMAM), a highly branched dendrimer, is available for loading a wide range of drug molecules and has shown the penetration capacity into threedimensional cell spheroids, intestines, and the skin as novel drug carriers [78-80]. However, the highly positive charge of PAMAM may cause toxicity to the epithelium, so PAMAM was modified with polyethylene glycol (PEG) to form biocompatible PEG-PAMAM, which could help DOX penetrate deeper into the bladder wall. The amount of DOX within the bladder tissues was also increased after intravesical installation [51].

Chitosan is a cationic polysaccharide with biocompatibility. Positively charged chitosan could facilitate adherence to the negatively charged mucosa, disrupt the biological barrier's integrity, loosen intercellular tight junctions, and facilitate paracellular drug transport [80-83]. The surface of poly(lactic-co-glycolic acid) (PLGA) nanoparticles (NP) were modified by low molecular weight chitosan, these chitosan-modified NPs demonstrated 10fold increased uptake in the mouse bladder than unmodified NPs, and chitosan-modified NPs encapsulated survivin siRNA resulted in about $65 \%$ reduction in bladder tumor volume [52]. Interleukin-12 (IL-12), a potent inducer of the innate immune system, was co-delivered with the chitosan (CS/IL-12) for intravesical treatment of bladder cancer. In vivo experiments suggested that chitosan enhanced the intravesical delivery of IL-12 to boost the anticancer effect [53].

Poly guanidinium oxanorbornene (PGON) is a positively charged cell-penetrating polymer, the addition of PGON to the surface of PLGA NPs significantly improved bladder penetration of NPs by 10-fold compared to NPs without PGON in the mouse bladder [54].

\subsection{Fluorinated Polymers}

Owing to unique hydrophobic and lipophobic behaviors of fluorocarbon, fluorinated polymers could be used as gene/protein carriers for effective transmembrane penetration [84-86]. Previous studies have proven that fluorinated polyethylenimine (F-PEI) could self-assemble with the mastoparan I (MPI) peptide, F-PEI significantly increased mucosal and tumor permeability of MPI in the bladder; therefore, intravesical treatment with MPI/F-PEI NPs resulted in remarkably improved therapeutic responses compared to other controls [55]. Moreover, Li et al. found fluorinated chitosan (FCS) could modulate transepithelial electrical resistance and open tight junctions of uroepithelium by transmission electron microscope, which performed better than PEI in the ability to improve transmucosal and intra-tumoral penetration. Moreover, FCS dramatically enhanced intravesical sonosensitizer conjugated catalase delivery for improving the treatment effectiveness of bladder cancer in vivo [56]. 


\subsection{Liposomes}

The liposome is an attractive drug delivery carrier with lipid bilayers that resembles the structure of cytomembranes. Maleimide-modified PEGylated (Mal-PEG) liposomes were developed as mucoadhesive vehicles for intravesical therapy of bladder cancer [57]. Mal-PEG liposomes encapsulated fluorescein sodium exhibited greater penetration and retention abilities on bladder mucosal compared to unmodified liposomes. GuhaSarkar et al. have designed an in situ-gelling liposome-in-gel (LP-Gel) system using fluidizing liposomes incorporated into gellan hydrogel [58]. LP-Gel utilizes urine to undergo ion-triggered gelation to form a cross-linked gellan matrix. The system mimics the bladder mucosa, thereby allowing better interaction and adhesion to the bladder wall. After LP-Gel system is instilled into the rat bladder, the ion-triggered gelation adheres to the urothelium, the fluidizing liposomes then penetrate through the urothelial barrier, therefore prolonging drug localization in tumor lesions. Instillation of paclitaxel-loaded LP-Gel showed prolonged drug localization in the bladder at least 7 days, suggesting potential use in clinical practice.

\subsection{Surfactants}

Surfactants are a series of compounds that lower the surface tension, which may act as detergents, emulsifiers, or dispersants. A few surfactants have been approved by FDA to promote penetration through the skin, such as sodium octyl sulfate and sodium laureth sulfate $[87,88]$. Some studies have also reported that surfactants could enhance urothelial penetration of adenoviruses and chemotherapeutic agents $[63,89]$. Adenovirus is one of the most promising vectors for gene therapy, the coxsackievirus and adenovirus receptor (CAR) mediates adenoviral attachment and infection by CAR-independent cell entry. However, the GAG layer retards the adenoviral adherence to the CAR of the urothelium, further reducing the therapeutic effect based on adenovirus gene vectors. Some surfactants could disrupt the GAG layer, such as dodecyl-beta-D-maltoside [32], sodium dodecyl sulfate [50], cetylpyridinium chloride [60], and Syn3 (a synthetic polyamide surfactant) [90]. Significantly, the intravesical gene therapy based on recombinant adenovirus with Syn3 (rAd-IFN $\alpha /$ Syn3) has been under clinical trials [63].

Tween 80 (polysorbate 80) is a nonionic surfactant often used in medicines and cosmetics, which has been found to enhance intravesical chemotherapy. The addition of Tween 80 could improve the doxorubicin concentration in the rat bladder wall [61]. The docetaxel solution (Taxotere ${ }^{\circledR}$, DTX-sol) also promotes the docetaxel absorption in the bladder tissue by adding Tween 80 . Besides, Brij 98, a polyoxyethylene surfactant, also could as the permeation enhancer for intravesical instillation. The low surface tension of Brij 98-containing nanoemulsions could facilitate cisplatin to permeate across urothelium, resulting in the high concentration and retention ability of cisplatin in the bladder tissues [62].

\subsection{Calcium Ion Chelators}

Calcium ions play an essential role in maintaining cell-cell junctions [91-93]. The removal of extracellular calcium in cultured epithelial cells could lead to the opening of intercellular tight junctions to enhance paracellular permeability [94]. Calcium ion chelators have been used in breaking tight junctions of the urothelium and intracellular junctions of bladder tumors. Polycarbophil is a synthetic polymer by the cross-linking of polyacrylic acid with divinyl glycol, which could chelate with extracellular calcium ions, resulting in the opening of cellular tight junctions [64,95]. In the isolated porcine bladder, intravesical polycarbophil $(1 \% w / v)$ increased the bladder tissue penetration of pipemidic acid by 4-fold. EDTA (Ethylenediaminetetraacetic acid) is an aminopolycarboxylic acid with the capacity to bind to calcium ions to form a hexadentate chelating agent [38]. Bao et al. have recently developed an innovative EDTA-based nano-platform, which can deprive $\mathrm{Ca}^{2+}$ from the intercellular calcium-dependent connexin by EDTA-Ca ${ }^{2+}$ chelation, resulting in the opening of intercellular junctions and the disaggregation of bladder cancer cells [65]. This non-invasive strategy presents excellent clinical prospects for intravesical therapy of bladder cancer. 


\subsection{Nanogels}

The intravesical instillation can be further improved by enhancing the drug mucoadhesive capacity, thereby preventing the drug from being washed away during urination. Nanogels are nanosized hydrogels formed by highly crosslinked polymer networks, which can be designed to prolong the retention period to the urothelium and penetrability of drugs toward the bladder wall [96]. The polypeptide nanogel of poly(Llysine) poly(L-phenylalanine-co-L-cystine) (PLL-P(LP-co-LC)) was synthesized to deliver 10-hydroxycamptothecin (HCPT) for treating orthotopic bladder cancer [66]. The positive surface charge and amphipathicity gave the nanogel excellent permeation and retention properties in the bladder wall, further boosting antitumor effect toward bladder cancer. In addition, a PEG-modified nanogel of oligoarginine-poly(ethylene glycol)-poly(Lphenylalanine-co-L-cystine) (R9-PEG-P(LP-co-LC)) was developed for intravesical instillation. Modification of PEG and R9 significantly improved HCPT-nanogel with enhanced mucoadhesiveness, owing to the nonspecific interaction between PEG chains and the urothelium along with the electrostatic interaction between the cationic R9 and the negatively charged bladder mucosa. Moreover, R9 further promoted the permeability of nanogel/HCPT into the bladder wall. The intravesical instillation of nanogel/HCPT remarkably inhibited tumor progression in the orthotopic bladder cancer model [67].

\subsection{Others}

Protamine is a positively charged protein that originated from salmon sperm. Protamine can damage the negatively charged GAG layer of urothelium through electrostatic interaction [97]. It is widely used to make experimental animal models of interstitial cystitis/bladder pain syndrome by inducing the bladder permeability barrier's dysfunction $[47,98]$. Hyaluronidase is an endoglycosidase with the ability to hydrolyze hyaluronic acid of the GAG layer to disrupt the integrity of urothelium [99]. Owing to severe damage to the bladder barrier function, protamine and hyaluronidase may not be suitable for intravesical therapy. The dysfunction of bladder penetrating barriers caused by protamine and hyaluronidase will be likely to result in undesirable side effects, such as increased urgency, frequency, and pain during urination.

\section{Physical Methods to Get Drugs across Bladder Penetrating Barriers \\ 6.1. Electromotive Drug Administration}

Electromotive drug administration (EMDA) is a widely used device-assisted intravesical therapy, which creates a potential gradient between the bladder wall and the intravesical drug solution under an electric field's influence $[68,100,101]$. The electrical field is generated between a catheter electrode placed on the bladder wall's surface and a cutaneous electrode sticking on the abdomen to aid the transport of drug molecules into tissues [69,102]. EMDA temporarily increases the drug permeability through the bladder barrier by electro-osmosis and electroporation [102]. EMDA increased the MMC uptake in bladder tissues, the MMC concentration was 30-fold higher using EMDA than passive MMC in the urothelium and three-fold higher in the lamina propria and muscularis [103]. In clinical trials, EMDA is considered safe and effective for high-risk NMIBC patients with "BCG refractory", which could be the salvage treatment for these patients to avoid radical cystectomy $[68,69]$.

\subsection{Radiofrequency-Induced Thermo-Chemotherapeutic Effect}

Radiofrequency-induced thermo-chemotherapeutic effect (RITE) has been developed to improve intravesical chemotherapy, especially for BCG-unresponsive NMIBC [104,105]. The minitype antenna in the catheter with radiofrequency at $915 \mathrm{MHz}$ is directed at the bladder wall. The thermo-energy induced by radiofrequency can effectively penetrate bladder tissue thickness to enhance tissue and cell permeability, so as to improve intravesical drug absorption [102]. Besides, bladder tumors are more susceptible to hyperthermia than normal tissues, and nanotubes on the cancer cell membrane induced by RITE further improve intracellular drug delivery [106,107]. Intravesical $40 \mathrm{mg}$ MMC combined with 
RITE over 60 min resulted in 10-fold higher MMC concentration in the bladder tumor tissue than intravesical MMC alone [108]. In a systematic analysis, only 26 out of $93(28.0 \%)$ patients had the bladder cancer recurrence in the RITE group, versus 67 out of $99(67.7 \%)$ in the MMC alone group, indicating lower recurrence risk in the RITE group than the MMC only group [70]. Besides, a recent study revealed patients with high-risk NMIBC and unresponsive/intolerant to BCG treatment would most likely benefit from this technology, the 24-month disease-free survival (RFS) was $81.8 \%$ in the RITE group, versus $64.8 \%$ in the BCG group [71].

\subsection{Shock Wave}

The extracorporeal shock wave has been applied for lithotripsy for decades $[109,110]$. Recently, low-energy shock wave (LESW) therapy has been reported to increase the cell and tissue permeability without apparent damage, which has been applied to ameliorate tissue ischemia and enhance intracellular delivery [111-113]. LESW can overcome the bladder barrier through acoustic pulses, thereby strengthening the drug's passive diffusion into the bladder wall to increase the local drug concentration. Elkashef et al. has investigated the effect of LESW on enhancing intravesical epirubicin delivery in a rat bladder cancer model. They found LESW enhanced urothelial permeability, and epirubicin concentration was increased by 5.7-fold compared to intravesical epirubicin alone. Moreover, LESW-assisted intravesical epirubicin therapy resulted in less tumor invasion and lower mortality rates [72]. Therefore, LESW may be a feasible device-assisted therapy for treating bladder cancer.

\subsection{Nanomotors}

Compared to passive diffusion, self-propelled nanomotors have shown great potential for applications in the active drug delivery [114-116]. Nanomotors with autonomous power are capable of enhancing tissue retention and penetration to overcome biological barriers $[117,118]$. Tang et al. have fabricated a type of nanometer by asymmetrically modifying platelets with the urease [73]. When these nanomotors are exposed to urea, the urease-mediated enzymatic reaction will produce carbon dioxide and ammonia to form the driving power, which actuates the motor for active movement. Polydopamine shows good biocompatibility and high adhesion property to biological tissues [119-121]. Choi et al. developed a polydopamine-based nanomotor, which was surface-functionalized with urease. When intravesical polydopamine-based nanomotors are exposed to the high level of urea in urine, they autonomously and efficiently penetrate deeply into the bladder mucosa and remain for a long period [74]. Nanomotors have opened the door for the active intravesical delivery to overcome bladder penetrating barriers. The enhanced penetration and retention of nanomotors as intravesical drug delivery vehicles will also be used to treat other bladder diseases.

\subsection{Focal Injury}

Griffin et al. found the peptide CGKRK (Cys-Gly-Lys-Arg-Lys) could penetrate mucosal layers following focal mechanical damage to the urothelium [122]. After the focal injury, the intravesical peptide could bind to the entire urothelium, further penetrating the deeper tissues than the control without the injury treatment. Moreover, rhodamine-loaded CGKRK-nanogels can also be effectively delivered to the bladder mucosa after the focal injury. The above results indicated that limited focal injury might be contributed to the entire intravesical delivery.

\section{Conclusions}

Intravesical drug therapy is an indispensable approach for treating bladder cancer. However, due to the existence of bladder penetrating barriers, the drug cannot effectively enter into the lesions after intravesical instillation, inadequate treatment will result in the recurrence of bladder cancer. In order to maximize the therapeutic effect of intravesical 
drugs, penetration enhanced strategies are essential. In previous studies, various physical and chemical methods have been applied to disrupt the bladder barrier to enhance drug permeability and increase the drug concentration of bladder tumors.

In the future, the efficacy and clinical feasibility need to be a concern to facilitate advanced strategies of penetrating bladder barriers into the clinical practice. The most promising strategies include liposomes, surfactants, nanogels, EMDA, RITE, and lowenergy shock wave therapy, some of which have been under clinical trials. Moreover, the combined strategies with different chemical and physical means have great potentials in improving the intravesical therapeutic effect. These developed strategies to get drugs across bladder penetrating barriers will be also used for intravesical therapy of other bladder diseases, such as overactive bladder, cystitis, etc.

Funding: This research was partially funded by the Youth Program of National Natural Science Foundation of China (81922046, 82000732, 81903090), the Basic and Applied Basic Research Foundation of Guangdong (2019A1515110176, 2019A1515110151, 2019A1515111050).

Conflicts of Interest: The authors declare no conflict of interest.

\section{References}

1. Patel, V.; Oh, W.K.; Galsky, M.D. Treatment of muscle-invasive and advanced bladder cancer in 2020. Cancer J. Clin. 2020, 70, 404-423. [CrossRef] [PubMed]

2. Grayson, M. Bladder cancer. Nature 2017, 551, S33. [CrossRef] [PubMed]

3. Mari, A.; D'Andrea, D.; Abufaraj, M.; Foerster, B.; Kimura, S.; Shariat, S.F. Genetic determinants for chemo- and radiotherapy resistance in bladder cancer. Transl. Androl. Urol. 2017, 6, 1081-1089. [CrossRef]

4. Cumberbatch, M.G.K.; Jubber, I.; Black, P.C.; Esperto, F.; Figueroa, J.D.; Kamat, A.M.; Kiemeney, L.; Lotan, Y.; Pang, K.; Silverman, D.T.; et al. Epidemiology of Bladder Cancer: A Systematic Review and Contemporary Update of Risk Factors in 2018. Eur. Urol. 2018, 74, 784-795. [CrossRef] [PubMed]

5. Glaser, A.P.; Fantini, D.; Shilatifard, A.; Schaeffer, E.M.; Meeks, J.J. The evolving genomic landscape of urothelial carcinoma. Nat. Rev. Urol. 2017, 14, 215-229. [CrossRef]

6. Cambier, S.; Sylvester, R.J.; Collette, L.; Gontero, P.; Brausi, M.A.; Van Andel, G.; Kirkels, W.J.; Da Silva, F.C.; Oosterlinck, W.; Prescott, S.; et al. EORTC Nomograms and Risk Groups for Predicting Recurrence, Progression, and Disease-specific and Overall Survival in Non-Muscle-invasive Stage Ta-T1 Urothelial Bladder Cancer Patients Treated with 1-3 Years of Maintenance Bacillus Calmette-Guérin. Eur. Urol. 2016, 69, 60-69. [CrossRef]

7. Colombo, R.; Van Valenberg, H.; Moschini, M.; Witjes, J.A. Radiofrequency-Induced Thermo-Chemotherapy Effect (Rite) for Non Muscle Invasive Bladder Cancer Treatment: Current Role and Perspectives. Urol. J. 2016, 83, 7-17. [CrossRef]

8. Pan, S.; Zhan, Y.; Chen, X.; Wu, B.; Liu, B. Identification of Biomarkers for Controlling Cancer Stem Cell Characteristics in Bladder Cancer by Network Analysis of Transcriptome Data Stemness Indices. Front. Oncol. 2019, 9, 613. [CrossRef]

9. Yang, Z.; Li, C.; Fan, Z.; Liu, H.; Zhang, X.; Cai, Z.; Xu, L.; Luo, J.; Huang, Y.; He, L.; et al. Single-cell Sequencing Reveals Variants in ARID1A, GPRC5A and MLL2 Driving Self-renewal of Human Bladder Cancer Stem Cells. Eur. Urol. 2017, 71, 8-12. [CrossRef]

10. Wu, S.; Ou, T.; Xing, N.; Lu, J.; Wan, S.; Wang, C.; Zhang, X.; Yang, F.; Huang, Y.; Cai, Z. Whole-genome sequencing identifies ADGRG6 enhancer mutations and FRS2 duplications as angiogenesis-related drivers in bladder cancer. Nat. Commun. 2019, 10, 1-12. [CrossRef]

11. Pan, S.; Zhan, Y.; Chen, X.; Wu, B.; Liu, B. Bladder Cancer Exhibiting High Immune Infiltration Shows the Lowest Response Rate to Immune Checkpoint Inhibitors. Front. Oncol. 2019, 9, 1101. [CrossRef] [PubMed]

12. Szabados, B.; Powles, T. Immune checkpoint inhibition in urothelial carcinoma. Lancet 2020, 395, 1522-1523. [CrossRef]

13. Richters, A.; Aben, K.K.H.; Kiemeney, L.A. The global burden of urinary bladder cancer: An update. World J. Urol. 2020, 38, 1895-1904. [CrossRef] [PubMed]

14. Tan, Z.M.; Lai, G.P.; Pandey, M.; Srichana, T.; Choudhury, H. Novel Approaches for the Treatment of Pulmonary Tuberculosis. Pharmaceutics 2020, 12, 1196. [CrossRef] [PubMed]

15. Mukherjee, N.; Wheeler, K.M.; Svatek, R.S. Bacillus Calmette-Guérin treatment of bladder cancer: A systematic review and commentary on recent publications. Curr. Opin. Urol. 2019, 29, 1. [CrossRef]

16. Alhunaidi, O.; Zlotta, A.R. The use of intravesical BCG in urothelial carcinoma of the bladder. Ecancermedicalscience 2019, $13,905$. [CrossRef]

17. Koch, G.E.; Smelser, W.W.; Chang, S.S. Side Effects of Intravesical BCG and Chemotherapy for Bladder Cancer: What They Are and How to Manage Them. Urology 2020. [CrossRef]

18. Domingos-Pereira, S.; Cesson, V.; Chevalier, M.F.; Derré, L.; Jichlinski, P.; Nardelli-Haefliger, D. Preclinical efficacy and safety of the Ty21a vaccine strain for intravesical immunotherapy of non-muscle-invasive bladder cancer. Oncoimmunology 2017, 6, e1265720. [CrossRef] 
19. Wientjes, M.G.; Badalament, R.A.; Au, J.L.-S. Use of pharmacologic data and computer simulations to design an efficacy trial of intravesical mitomycin C therapy for superficial bladder cancer. Cancer Chemother. Pharmacol. 1993, 32, 255-262. [CrossRef]

20. Milbar, N.; Kates, M.; Chappidi, M.R.; Schoenberg, M.P.; Bivalacqua, T. Oncological outcomes of intravesical gemcitabine and docetaxel for select patients with high grade recurrent NMIBC. J. Clin. Oncol. 2017, 35, 4546. [CrossRef]

21. Cockerill, P.A.; Knoedler, J.J.; Frank, I.; Tarrell, R.; Karnes, R.J. Intravesical gemcitabine in combination with mitomycin C as salvage treatment in recurrent non-muscle-invasive bladder cancer. BJU Int. 2015, 117, 456-462. [CrossRef] [PubMed]

22. Au, J.L.-S.; Badalament, R.A.; Wientjes, M.G.; Young, D.C.; Warner, J.A.; Venema, P.L.; Pollifrone, D.L.; Harbrecht, J.D.; Chin, J.L.; Lerner, S.P.; et al. Methods to Improve Efficacy of Intravesical Mitomycin C: Results of a Randomized Phase III Trial. J. Natl. Cancer Inst. 2001, 93, 597-604. [CrossRef] [PubMed]

23. Steinberg, R.L.; Thomas, L.J.; O'Donnell, M.A. Combination intravesical chemotherapy for non-muscle-invasive bladder cancer. Eur. Urol. Focus 2018, 4, 503-505. [CrossRef] [PubMed]

24. DeCastro, G.; Sui, W.; Pak, J.; Abate-Shen, C.; Lee, S.; Anderson, C.; Holder, D.; McKiernan, J. Mp15-13 A Phase I Trial for The Use of Intravesical Cabazitaxel, Gemcitabine, and Cisplatin (Cgc) In the Treatment Of Bcg-Refractory Non-Muscle Invasive Urothelial Carcinoma Of The Bladder. J. Urol. 2017, 197, e175-e176. [CrossRef]

25. Chen, T.-Y.; Tsai, M.-J.; Chang, L.-C.; Wu, P.-C. Co-Delivery of Cisplatin and Gemcitabine via Viscous Nanoemulsion for Potential Synergistic Intravesical Chemotherapy. Pharmaceutics 2020, 12, 949. [CrossRef] [PubMed]

26. Hendricksen, K. Device-assisted intravesical therapy for non-muscle invasive bladder cancer. Transl. Androl. Urol. 2019, 8, 94-100. [CrossRef] [PubMed]

27. Berndt-Paetz, M.; Schulze, P.; Stenglein, P.C.; Weimann, A.; Wang, Q.; Horn, L.-C.; Riyad, Y.M.; Griebel, J.; Hermann, R.; Glasow, A. Reduction of muscle-invasive tumors by photodynamic therapy with Tetrahydroporphyrin-Tetratosylat in an ortho-topic rat bladder Cancer model. Mol. Cancer Ther. 2019, 18, 743-750. [CrossRef] [PubMed]

28. Lin, T.; Zhao, X.; Zhao, S.; Yu, H.; Cao, W.; Chen, W.; Wei, H.; Guo, H. $\mathrm{O}_{2}$-generating $\mathrm{MnO}_{2}$ nanoparticles for enhanced photodynamic therapy of bladder cancer by ameliorating hypoxia. Theranostics 2018, 8, 990-1004. [CrossRef] [PubMed]

29. Railkar, R.; Agarwal, P.K. Photodynamic therapy in the treatment of bladder cancer: Past challenges and current innova-tions. Eur. Urol. Focus 2018, 4, 509-511. [CrossRef] [PubMed]

30. Chou, R.; Selph, S.; Buckley, D.I.; Fu, R.; Griffin, J.C.; Grusing, S.; Gore, J.L. Comparative effectiveness of fluorescent versus white light cystoscopy for initial diagnosis or surveillance of bladder cancer on clinical outcomes: Systematic review and meta-analysis. J. Urol. 2017, 197, 548-558. [CrossRef] [PubMed]

31. Witjes, J.A.; Douglass, J. The role of hexaminolevulinate fluorescence cystoscopy in bladder cancer. Nat. Clin. Pr. Urol. 2007, 4, 542-549. [CrossRef] [PubMed]

32. Packiam, V.T.; Lamm, D.L.; Barocas, D.A.; Trainer, A.; Fand, B.; Davis, R.L.; Clark, W.; Kroeger, M.; Dumbadze, I.; Chamie, K.; et al. An open label, single-arm, phase II multicenter study of the safety and efficacy of CG0070 oncolytic vector regimen in patients with BCG-unresponsive non-muscle-invasive bladder cancer: Interim results. Urol. Oncol. Semin. Orig. Investig. 2018, 36, 440-447. [CrossRef] [PubMed]

33. Packiam, V.T.; Barocas, D.A.; Chamie, K.; Davis, R.L.; Kader, A.K.; Lamm, D.L.; Dorr, K.; Gutheil, J.; Kuan, A.; Steinberg, G.D. MP43-02 CG0070, An Oncolytic Adenovirus, For BCG-Unresponsive Non-Muscle-Invasive Bladder Cancer (Nmibc): 18 Month Follow-Up From A Multicenter Phase II Trial. J. Urol. 2019, 201 (Suppl. 4), e617. [CrossRef]

34. Packiam, V.T.; Barocas, D.A.; Chamie, K.; Davis, R.L., III; Kader, K.; Lamm, D.L.; Curran, D.; Yeung, A.W.; Steinberg, G.D. PNFLBA-13 Interim Results From A Single-Arm Multicenter Phase II Trial Of CG0070, An Oncolytic Adenovirus, For BCGUnresponsive Non-Muscle-Invasive Bladder Cancer (NMIBC). J. Urol. 2017, 197, e915-e916. [CrossRef]

35. Pfail, J.L.; Katims, A.B.; Alerasool, P.; Sfakianos, J.P. Immunotherapy in non-muscle-invasive bladder cancer: Current status and future directions. World J. Urol. 2020. [CrossRef] [PubMed]

36. Nykopp, T.K.; Da Costa, J.B.; Mannas, M.; Black, P.C. Current Clinical Trials in Non-muscle Invasive Bladder Cancer. Curr. Urol. Rep. 2018, 19, 101. [CrossRef] [PubMed]

37. Chou, R.; Selph, S.; Buckley, D.I.; Fu, R.; Griffin, J.C.; Grusing, S.; Gore, J.L. Intravesical Therapy for the Treatment of Nonmuscle Invasive Bladder Cancer: A Systematic Review and Meta-Analysis. J. Urol. 2017, 197, 1189-1199. [CrossRef]

38. Christensen, T.; Gooden, D.M.; Kung, J.E.; Toone, E.J. Additivity and the physical basis of multivalency effects: A thermo-dynamic investigation of the calcium EDTA interaction. J. Am. Chem. Soc. 2003, 125, 7357-7366. [CrossRef]

39. Carattino, M.D.; Prakasam, H.S.; Ruiz, W.G.; Clayton, D.R.; McGuire, M.; Gallo, L.I.; Apodaca, G. Bladder filling and voiding affect umbrella cell tight junction organization and function. Am. J. Physiol. Physiol. 2013, 305, F1158-F1168. [CrossRef]

40. Kreft, M.E.; Hudoklin, S.; Jezernik, K.; Romih, R. Formation and maintenance of blood-urine barrier in urothelium. Protoplasma 2010, 246, 3-14. [CrossRef]

41. Lasič, E.; Višnjar, T.; Kreft, M.E. Properties of the Urothelium that Establish the Blood-Urine Barrier and Their Implications for Drug Delivery. Rev. Physiol. Biochem. Pharmacol. 2015, 168, 1-29. [CrossRef] [PubMed]

42. Janssen, D.A.; Van Wijk, X.M.; Jansen, K.C.; Van Kuppevelt, T.H.; Heesakkers, J.P.; Schalken, J.A. The Distribution and Function of Chondroitin Sulfate and Other Sulfated Glycosaminoglycans in the Human Bladder and Their Contribution to the Protective Bladder Barrier. J. Urol. 2013, 189, 336-342. [CrossRef] [PubMed]

43. Klingler, C.H. Glycosaminoglycans: How Much do We Know about their Role in the Bladder? Urol. J. 2016, 83, 11-14. [CrossRef] [PubMed] 
44. Lilly, J.D.; Parsons, C.L. Bladder surface glycosaminoglycans is a human epithelial permeability barrier. Surg. Gynecol. Obstet. 1990, 171, 493. [PubMed]

45. Lavelle, J.P.; Meyers, S.; Ramage, R.; Bastacky, S.; Doty, D.; Apodaca, G.; Zeidel, M.L. Bladder permeability barrier: Recovery from selective injury of surface epithelial cells. Am. J. Physiol. Physiol. 2002, 283, F242-F253. [CrossRef]

46. Erman, A.; Kos, M.K.; Žakelj, S.; Resnik, N.; Romih, R.; Veranič, P. Correlative study of functional and structural regeneration of urothelium after chitosan-induced injury. Histochem. Cell Biol. 2013, 140, 521-531. [CrossRef]

47. Rozenberg, B.B.; Janssen, D.A.W.; Jansen, C.F.J.; Schalken, J.A.; Heesakkers, J.P. Improving the barrier function of damaged cultured urothelium using chondroitin sulfate. Neurourol. Urodyn. 2019, 39, 558-564. [CrossRef]

48. Yaman, Ö.; Özdiler, E.; Özen, S.; Gögüş, O. Transmurally absorbed intravesical chemotherapy with dimethylsulfoxide in an animal model. Int. J. Urol. 1999, 6, 87-92. [CrossRef]

49. Badalament, R.A.; Franklin, G.L.; Page, C.M.; Dasani, B.M.; Wientjes, M.G.; Drago, J.R. Enhancement of Bacillus Calmette-Guerin Attachment to the Urothelium by Removal of the Rabbit Bladder Mucin Layer. J. Urol. 1992, 147, 482-485. [CrossRef]

50. Ramesh, N.; Memarzadeh, B.; Ge, Y.; Frey, D.; VanRoey, M.; Rojas, V.; Yu, D. Identification of Pretreatment Agents to Enhance Adenovirus Infection of Bladder Epithelium. Mol. Ther. 2004, 10, 697-705. [CrossRef]

51. Qiu, X.; Cao, K.; Lin, T.; Chen, W.; Yuan, A.; Wu, J.; Hu, Y.; Guo, H. Drug delivery system based on dendritic nanoparticles for enhancement of intravesical instillation. Int. J. Nanomed. 2017, 12, 7365-7374. [CrossRef] [PubMed]

52. Martin, D.T.; Steinbach, J.M.; Liu, J.; Shimizu, S.; Kaimakliotis, H.Z.; Wheeler, M.A.; Hittelman, A.B.; Saltzman, W.M.; Weiss, R.M. Surface-Modified Nanoparticles Enhance Transurothelial Penetration and Delivery of Survivin siRNA in Treating Bladder Cancer. Mol. Cancer Ther. 2014, 13, 71-81. [CrossRef] [PubMed]

53. Smith, S.G.; Baltz, J.L.; Koppolu, B.P.; Ravindranathan, S.; Nguyen, K.; Zaharoff, D.A. Immunological mechanisms of intravesical chitosan/interleukin-12 immunotherapy against murine bladder cancer. OncoImmunology 2017. [CrossRef]

54. Martin, D.T.; Hoimes, C.J.; Kaimakliotis, H.Z.; Cheng, C.J.; Zhang, K.; Liu, J.; Wheeler, M.A.; Kelly, W.K.; Tew, G.N.; Saltzman, W.M.; et al. Nanoparticles for urothelium penetration and delivery of the histone deacetylase inhibitor belinostat for treatment of bladder cancer. Nanomed. Nanotechnol. Biol. Med. 2013, 9, 1124-1134. [CrossRef] [PubMed]

55. Li, G.; Lei, Q.; Wang, F.; Deng, D.; Wang, S.; Tian, L.; Shen, W.; Cheng, Y.; Liu, Z.; Wu, S. Fluorinated Polymer Mediated Transmucosal Peptide Delivery for Intravesical Instillation Therapy of Bladder Cancer. Small 2019, 15, e1900936. [CrossRef]

56. Li, G.; Wang, S.; Deng, D.; Xiao, Z.; Dong, Z.; Wang, Z.; Lei, Q.; Gao, S.; Huang, G.; Zhang, E.; et al. Fluorinated Chitosan To Enhance Transmucosal Delivery of Sonosensitizer-Conjugated Catalase for Sonodynamic Bladder Cancer Treatment Postintravesical Instillation. ACS Nano 2020, 14, 1586-1599. [CrossRef]

57. Kaldybekov, D.B.; Tonglairoum, P.; Opanasopit, P.; Khutoryanskiy, V.V. Mucoadhesive maleimide-functionalised liposomes for drug delivery to urinary bladder. Eur. J. Pharm. Sci. 2018, 111, 83-90. [CrossRef]

58. GuhaSarkar, S.; More, P.; Banerjee, R. Urothelium-adherent, ion-triggered liposome-in-gel system as a platform for in-travesical drug delivery. J. Control. Release 2017, 245, 147-156. [CrossRef]

59. Oefelein, M.; Huynh, D.; Dickstein, R.; Bean, K. MP72-01 Phase 1 Outcomes of a Novel Third Generation Liposomal Paclitaxel Formulation (TSD-001) In Low-Intermediate Risk Non-Muscle Invasive Bladder Cancer (NMIBC) Patients. J. Urol. 2020, 203, e1073. [CrossRef]

60. Grist, M.; Chakraborty, J. Identification of a mucin layerin the urinary bladder. Urology 1994, 44, 26-33. [CrossRef]

61. Hellsten, S.; Axelsson, B.; Eksborg, S.; Lindkvist, C. Organ distribution of Adriamycin ${ }^{\circledR}$ after intravesical instillation with or without Tween 80 in the rat. Urol. Res. 1988, 16, 325-327. [CrossRef] [PubMed]

62. Hwang, T.-L.; Fang, C.-L.; Chen, C.-H.; Fang, J.-Y. Permeation Enhancer-Containing Water-In-Oil Nanoemulsions as Carriers for Intravesical Cisplatin Delivery. Pharm. Res. 2009, 26, 2314-2323. [CrossRef] [PubMed]

63. Shore, N.D.; Boorjian, S.A.; Canter, D.J.; Ogan, K.; Karsh, L.I.; Downs, T.M.; Gomella, L.G.; Kamat, A.M.; Lotan, Y.; Svatek, R.S. Intravesical $\mathrm{rAd}$-IFN $\alpha / \mathrm{Syn} 3$ for patients with high-grade, bacillus calmette-guerin-refractory or relapsed non-muscle-invasive bladder cancer: A phase II randomized study. J. Clin. Oncol. 2017, 35, 3410. [CrossRef]

64. Grabnar, I.; Bogataj, M.; Mrhar, A. Influence of chitosan and polycarbophil on permeation of a model hydrophilic drug into the urinary bladder wall. Int. J. Pharm. 2003, 256, 167-173. [CrossRef]

65. Bao, Q.; Hu, P.; Ren, W.; Guo, Y.; Shi, J. Tumor Cell Dissociation Removes Malignant Bladder Tumors. Chem 2020, 6, 2283-2299. [CrossRef]

66. Guo, H.; Xu, W.; Chen, J.; Yan, L.; Ding, J.; Hou, Y.; Zhu, X. Positively charged polypeptide nanogel enhances mucoadhesion and penetrability of 10-hydroxycamptothecin in orthotopic bladder carcinoma. J. Control. Release 2017, 259, 136-148. [CrossRef] [PubMed]

67. Guo, H.; Li, F.; Qiu, H.; Xu, W.; Li, P.; Hou, Y.; Ding, J.; Chen, X. Synergistically Enhanced Mucoadhesive and Penetrable Polypeptide Nanogel for Efficient Drug Delivery to Orthotopic Bladder Cancer. Research 2020, 2020, 1-14. [CrossRef] [PubMed]

68. Carando, R.; Zazzara, M.; Cotrufo, S.; Ludovico, G.M. Intravesical Treatment with Electro-Mediated Administration of Mytomicin C as Prophylaxis for Intermediate and High-Risk Nonmuscle-Invasive Bladder Cancer: A Retrospective Multicenter Study. Urol. Int. 2019, 103, 285-290. [CrossRef]

69. Racioppi, M.; Di Gianfrancesco, L.; Ragonese, M.; Di Gianfrancesco, L.; Sacco, E.; Bassi, P.F. ElectroMotive drug administration (EMDA) of Mitomycin C as first-line salvage therapy in high risk "BCG failure" non muscle invasive bladder cancer: 3 years follow-up outcomes. BMC Cancer 2018, 18, 1-9. [CrossRef] 
70. Lammers, R.J.; Witjes, J.A.; Inman, B.A.; Leibovitch, I.; Laufer, M.; Nativ, O.; Colombo, R. The Role of a Combined Regimen With Intravesical Chemotherapy and Hyperthermia in the Management of Non-muscle-invasive Bladder Cancer: A Systematic Review. Eur. Urol. 2011, 60, 81-93. [CrossRef]

71. Arends, T.J.H.; Nativ, O.; Maffezzini, M.; De Cobelli, O.; Canepa, G.; Verweij, F.; Moskovitz, B.; Van Der Heijden, A.G.; Witjes, J.A. Results of a Randomised Controlled Trial Comparing Intravesical Chemohyperthermia with Mitomycin C Versus Bacillus Calmette-Guérin for Adjuvant Treatment of Patients with Intermediate- and High-risk Non-Muscle-invasive Bladder Cancer. Eur. Urol. 2016, 69, 1046-1052. [CrossRef] [PubMed]

72. Elkashef, A.; Barakat, N.; Khater, S.M.; Awadalla, A.; Belal, F.; El-Assmy, A.M.; Sheir, K.Z.; Shokeir, A.A. Effect of low-energy shock wave therapy on intravesical epirubicin delivery in a rat model of bladder cancer. BJU Int. 2021, 127, 80-89. [CrossRef] [PubMed]

73. Tang, S.; Zhang, F.; Gong, H.; Wei, F.; Zhuang, J.; Karshalev, E.; De Ávila, B.E.-F.; Huang, C.; Zhou, Z.; Li, Z.; et al. Enzyme-powered Janus platelet cell robots for active and targeted drug delivery. Sci. Robot. 2020, 5, eaba6137. [CrossRef] [PubMed]

74. Choi, H.; Cho, S.H.; Hahn, S.K. Urease-Powered Polydopamine Nanomotors for Intravesical Therapy of Bladder Diseases. ACS Nano 2020, 14, 6683-6692. [CrossRef]

75. Rawls, W.F.; Cox, L.; Rovner, E. Dimethyl sulfoxide (DMSO) as intravesical therapy for interstitial cystitis/bladder pain syndrome: A review. Neurourol. Urodyn. 2017, 36, 1677-1684. [CrossRef] [PubMed]

76. Shen, Z.; Shen, T.; Wientjes, M.G.; O’Donnell, M.A.; Au, J.L.-S. Intravesical treatments of bladder cancer. Pharm. Res. 2008, 25, 1500-1510. [CrossRef]

77. Chen, D.; Song, D.; Wientjes, M.G.; Au, J.L.-S. Effect of dimethyl sulfoxide on bladder tissue penetration of intravesical paclitaxel. Clin. Cancer Res. 2003, 9, 363-369.

78. Jiang, L.-Y.; Lv, B.; Luo, Y. The effects of an RGD-PAMAM dendrimer conjugate in 3D spheroid culture on cell proliferation, expression and aggregation. Biomaterials 2013, 34, 2665-2673. [CrossRef]

79. Wiwattanapatapee, R.; Carreño-Gómez, B.; Malik, N.; Duncan, R. Anionic PAMAM dendrimers rapidly cross adult rat intestine in vitro: A potential oral delivery system? Pharm. Res. 2000, 17, 991-998. [CrossRef]

80. Venuganti, V.V.K.; Perumal, O.P. Effect of poly(amidoamine) (PAMAM) dendrimer on skin permeation of 5-fluorouracil. Int. J. Pharm. 2008, 361, 230-238. [CrossRef]

81. Wang, J.; Kong, M.; Zhou, Z.; Yan, D.; Yu, X.; Cheng, X.; Feng, C.; Liu, Y.; Chen, X. Mechanism of surface charge triggered intestinal epithelial tight junction opening upon chitosan nanoparticles for insulin oral delivery. Carbohydr. Polym. 2017, 157, 596-602. [CrossRef] [PubMed]

82. Schuerer, N.; Stein, E.; Inic-Kanada, A.; Ghasemian, E.; Stojanović, M.; Montanaro, J.; Bintner, N.; Hohenadl, C.; Sachsenhofer, R.; Barisani-Asenbauer, T. Effects of chitosan and chitosan N-acetylcysteine solutions on conjunctival epithelial cells. J. EuCornea 2018, 1, 12-18. [CrossRef]

83. Ali, A.; Ahmed, S. A review on chitosan and its nanocomposites in drug delivery. Int. J. Biol. Macromol. 2018, 109, 273-286. [CrossRef] [PubMed]

84. Xiao, Y.-P.; Zhang, J.; Liu, Y.-H.; Huang, Z.; Yu, X.-Q. Fluorinated polymer emulsion systems: Construction and application in delivering genes and proteins. Eur. J. Med. Chem. 2020, 207, 112799. [CrossRef]

85. Cheng, Y.-Y. Fluorinated polymers in gene delivery. Acta Polym. Sin. 2017, 8, 1234-1245.

86. Liu, H.; Wang, Y.; Wang, M.; Xiao, J.; Cheng, Y. Fluorinated poly(propylenimine) dendrimers as gene vectors. Biomaterials 2014, 35, 5407-5413. [CrossRef]

87. Yang, R.; Weiping, W.; Goldberg, H.; Wang, W.; Cullion, K.; Kohane, D.S. Getting Drugs Across Biological Barriers. Adv. Mater. 2017, 29, 1606596. [CrossRef]

88. Morris, S.A.; McCardy, N.; Thompson, R.; Allen, T.; Altemeier, A.; Wehmeyer, K.; Hinkle, R.; Jones, M.; Spruell, R.; Stoffolano, P.; et al. Comparing Surfactant Penetration into Human Skin and Resulting Skin Dryness Using In Vivo and Ex Vivo Methods. J. Cosmet. Sci. 2019, 70, 33-45.

89. Hamada, A.; Kita, Y.; Murakami, K.; Matsumoto, K.; Sakatani, T.; Sano, T.; Ogawa, O.; Kobayashi, T. Enhancement of transduction efficiency using Adeno-associated viral vectors by chemical pretreatment to mice bladder urothelium. J. Virol. Methods 2020, 279, 113854. [CrossRef]

90. Boorjian, S.A.; Alemozaffar, M.; Konety, B.R.; Shore, N.D.; Gomella, L.G.; Kamat, A.M.; Bivalacqua, T.J.; Montgomery, J.S.; Lerner, S.P.; Busby, J.E.; et al. Intravesical nadofaragene firadenovec gene therapy for BCG-unresponsive non-muscle-invasive bladder cancer: A single-arm, open-label, repeat-dose clinical trial. Lancet Oncol. 2021, 22, 107-117. [CrossRef]

91. Kim, S.A.; Tai, C.-Y.; Mok, L.-P.; Mosser, E.A.; Schuman, E.M. Calcium-dependent dynamics of cadherin interactions at cell-cell junctions. Proc. Natl. Acad. Sci. USA 2011, 108, 9857-9862. [CrossRef] [PubMed]

92. Adil, M.S.; Narayanan, S.P.; Somanath, P.R. Cell-cell junctions: Structure and regulation in physiology and pathology. Tissue Barriers 2020, 1848212. [CrossRef] [PubMed]

93. Lodish, H.; Berk, A.; Zipursky, S.L.; Matsudaira, P.; Baltimore, D.; Darnell, J. Cell-Cell Adhesion and Communication. In Molecular Cell Biology, 4th ed.; WH Freeman: New York, NY, USA, 2000.

94. Hardy, M.A. Intracellular calcium as a modulator of transepithelial permeability to water in frog urinary bladder. J. Cell Biol. 1978, 76, 787-791. [CrossRef] [PubMed] 
95. Kerec, M.; Bogataj, M.; Veranič, P.; Mrhar, A. Permeability of pig urinary bladder wall: The effect of chitosan and the role of calcium. Eur. J. Pharm. Sci. 2005, 25, 113-121. [CrossRef]

96. Guo, H.; Li, F.; Xu, W.; Chen, J.; Hou, Y.; Wang, C.; Ding, J.; Chen, X. Mucoadhesive cationic polypeptide nanogel with en-hanced penetration for efficient intravesical chemotherapy of bladder cancer. Adv. Sci. 2018, 5, 1800004. [CrossRef]

97. Parsons, C.L.; Argade, S.; Evans, R.J.; Proctor, J.; Nickel, J.C.; Rosenberg, M.T.; Bosch, P.C. Role of urinary cations in the etiology of interstitial cystitis: A multisite study. Int. J. Urol. 2020, 27, 731-735. [CrossRef]

98. Tajana, G.; Cervigni, M. Clinical Pathophysiology and Molecular Biology of the Urothelium and the GAG Layer. In Bladder Pain Syndrome; Springer: Boston, MA, USA, 2013; pp. 37-70.

99. Lv, Y.S.; Yao, Y.; Rong, L.; Lin, M.E.; Deng, B.H.; Xie, Y.; Huang, H.; Lin, T.X.; Xu, K.W.; Huang, J. Intravesical hyaluronidase causes chronic cystitis in a rat model: A potential model of bladder pain syndrome/interstitial cystitis. Int. J. Urol. 2013, 21, 601-607. [CrossRef]

100. Juvet, T.; Mari, A.; Lajkosz, K.; Wallis, C.J.; Kuk, C.; Erlich, A.; Krimus, L.; Fleshner, N.E.; Kulkarni, G.S.; Zlotta, A.R. Sequential administration of Bacillus Calmette-Guerin (BCG) and Electromotive Drug Administration (EMDA) of mitomycin C (MMC) for the treatment of high-grade nonmuscle invasive bladder cancer after BCG failure. Urol. Oncol. Semin. Orig. Investig. 2020, 38, e9-e15. [CrossRef]

101. Rehme, C.; Niedworok, C.; Rübben, H.; Vom Dorp, F. Non-muscle invasive bladder cancer: Safety of postoperative EMDA-assisted instillation of mitomycin. Urol. Ausg. 2015, 54, 235-238. [CrossRef]

102. Tan, W.S.; Kelly, J.D. Intravesical device-assisted therapies for non-muscle-invasive bladder cancer. Nat. Rev. Urol. 2018, 15, 667-685. [CrossRef]

103. Di Stasi, S.M.; Giannantoni, A.; Massoud, R.; Dolci, S.; Navarra, P.; Vespasiani, G.; Stephen, R.L. Electromotive versus passive diffusion of mitomycin C into human bladder wall: Concentration-depth profiles studies. Cancer Res. 1999, 59, $4912-4918$. [PubMed]

104. Tan, W.P.; Longo, T.A.; Inman, B.A. Heated Intravesical Chemotherapy: Biology and Clinical Utility. Urol. Clin. 2020, 47, 55-72. [CrossRef] [PubMed]

105. Sri, D.; Lee, H.J.; El-Gemmal, S.; Backhouse, C.; Tay, A.; John, B.; Perry, M.J.; Ayres, B.E.; Issa, R. Cystectomy outcomes in patients who have failed Radiofrequency-induced Thermo-chemotherapeutic Effect Mitomycin-C (RITE-MMC) treatment for high-risk non-muscle invasive bladder cancer (HRNMIBC)-Does it complicate surgery and adversely impact oncological outcome? Urol. Oncol. Semin. Orig. Investig. 2020. [CrossRef]

106. Paroni, R.; Salonia, A.; Lev, A.; Da Pozzo, L.F.; Cighetti, G.; Montorsi, F.; Rigatti, P.; Colombo, R. Effect of local hyperthermia of the bladder on mitomycin $C$ pharmacokinetics during intravesical chemotherapy for the treatment of superficial transitional cell carcinoma. Br. J. Clin. Pharmacol. 2001, 52, 273-278. [CrossRef]

107. Ware, M.J.; Tinger, S.; Colbert, K.L.; Corr, S.J.; Rees, P.; Koshkina, N.; Curley, S.; Summers, H.D.; Godin, B. Radiofrequency treatment alters cancer cell phenotype. Sci. Rep. 2015, 5, 12083. [CrossRef]

108. Van Valenberg, F.J.P.; Van Der Heijden, A.G.; Lammers, R.J.M.; Falke, J.; Arends, T.J.H.; Oosterwijk, E.; Witjes, J.A. Intravesical radiofrequency induced hyperthermia enhances mitomycin C accumulation in tumour tissue. Int. J. Hyperth. 2017, 34, 988-993. [CrossRef]

109. Veld, J.V.; van Huijgevoort, N.C.; Boermeester, M.A.; Besselink, M.G.; van Delden, O.M.; Fockens, P.; van Hooft, J.E. A systematic review of advanced endoscopy-assisted lithotripsy for retained biliary tract stones: Laser, electrohydraulic or ex-tracorporeal shock wave. Endoscopy 2018, 50, 896-909. [CrossRef]

110. Mateu, P.B.; Alba, A.B.; Liatsikos, E.; Villa, M.T.; López-Acón, J.; Ordaz, D.D.G.; Tormo, F.B. Is extracorporeal shock wave lithotripsy a current treatment for urolithiasis? A systematic review. Actas Urológicas Españolas 2017, 41, 426-434. [CrossRef]

111. Fojecki, G.L.; Tiessen, S.; Osther, P.J. Effect of low-energy linear shockwave therapy on erectile dysfunction-A double-blinded, sham-controlled, randomized clinical trial. J. Sex. Med. 2017, 14, 106-112. [CrossRef]

112. Hsiao, C.; Huang, W.-H.; Cheng, K.-H.; Lee, C.-T. Low-Energy Extracorporeal Shock Wave Therapy Ameliorates Kidney Function in Diabetic Nephropathy. Oxidative Med. Cell. Longev. 2019, 2019, 1-12. [CrossRef]

113. Nageib, M.; Zahran, M.H.; El-Hefnawy, A.S.; Barakat, N.; Awadalla, A.; Aamer, H.G.; Khater, S.; Shokeir, A.A. Low energy shock wave-delivered intravesical botulinum neurotoxin-A potentiates antioxidant genes and inhibits proinflammatory cytokines in rat model of overactive bladder. Neurourol. Urodyn. 2020, 39, 2447-2454. [CrossRef] [PubMed]

114. Xuan, M.; Shao, J.; Gao, C.; Wang, W.; Dai, L.; He, Q. Self-Propelled Nanomotors for Thermomechanically Percolating Cell Membranes. Angew. Chem. Int. Ed. 2018, 57, 12463-12467. [CrossRef] [PubMed]

115. Ortiz-Rivera, I.; Mathesh, M.; Wilson, D.A. A Supramolecular Approach to Nanoscale Motion: Polymersome-Based Self-Propelled Nanomotors. Acc. Chem. Res. 2018, 51, 1891-1900. [CrossRef]

116. Xu, D.; Wang, Y.; Liang, C.; You, Y.; Sanchez, S.; Ma, X. Self-Propelled Micro/Nanomotors for On-Demand Biomedical Cargo Transportation. Small 2019, 16, 1902464. [CrossRef] [PubMed]

117. Tezel, G.; Timur, S.S.; Kuralay, F.; Gürsoy, R.N.; Ulubayram, K.; Öner, L.; Eroglu, H. Current status of micro/nanomotors in drug delivery. J. Drug Target. 2021, 29, 29-45. [CrossRef]

118. Peifeng, S.; Hongxin, W.; Yongming, C.; Fei, P. Micro/nanomotors as drug delivery agent. Prog. Chem. $2019,31,63$.

119. Ryu, J.H.; Messersmith, P.B.; Lee, H. Polydopamine Surface Chemistry: A Decade of Discovery. ACS Appl. Mater. Interfaces 2018, 10, 7523-7540. [CrossRef] 
120. Ho, C.-C.; Ding, S.-J. Structure, Properties and Applications of Mussel-Inspired Polydopamine. J. Biomed. Nanotechnol. 2014, 10, 3063-3084. [CrossRef]

121. Ku, S.H.; Lee, J.S.; Park, C.B. Spatial Control of Cell Adhesion and Patterning through Mussel-Inspired Surface Modification by Polydopamine. Langmuir 2010, 26, 15104-15108. [CrossRef]

122. Griffin, J.I.; Cheng, S.K.; Hayashi, T.; Carson, D.; Saraswathy, M.; Nair, D.P.; Simberg, D. Cell-penetrating peptide CGKRK mediates efficient and widespread targeting of bladder mucosa following focal injury. Nanomed. Nanotechnol. Biol. Med. 2017, 13, 1925-1932. [CrossRef] 